\title{
MIELINÓLISE PONTINA CENTRAL PÓS-TRANSPLANTE HEPÁTICO
}

Túlio Marcus Ribeiro Bellard ${ }^{1}$, Christian Marques Couto², José Teotônio de Oliveira ${ }^{3}$, Antonio Lucio Teixeira JunioR ${ }^{* 4}$

Trabalho realizado no Serviço de Neurologia do Hospital das Clínicas da Universidade Federal de Minas Gerais - UFMG, Belo Horizonte, MG

Unitermos: Mielinólise pontina. Hipernatremia. Transplante de Fígado.

KEY WORDS: Pontine myelinolysis. Hypernatremia. Liver transplantation.

Trata-se de paciente do sexo feminino, 29 anos, admitida no Centro de Tratamento Intensivo do Hospital das Clínicas da UFMG com o diagnóstico de hepatite fulminante aguda de etiologia desconhecida.

O exame neurológico de admissão mostrou quadro compatível com encefalopatia hepática, exibindo confusão mental, hiperreflexia generalizada, asteríxis, mas sem sinais focais. Foi submetida a transplante hepático, procedimento que transcorreu sem maiores intercorrências, tendo recebido $600 \mathrm{~mL}$ de plasma fresco congelado no transoperatório.

No $2^{\circ}$ dia de pós-operatório, foi retirada da ventilação mecânica, mantendo estabilidade dos parâmetros clínicos. No entanto, chamava a atenção o quadro neurológico marcado por anartria e tetraplegia espástica com sinal de Babinski bilateral. Acompanhava o examinador com o olhar horizontal, mas não obedecia a ordens.

Foi realizada ressonância magnética do encéfalo que mostrou imagem hiperintensa de forma triangular no centro da ponte nas sequências ponderadas em T2 (Figura 1) e FLAIR (Figura 2). A imagem sagital em T1(Figura 3) mostrou imagem hipointensa na mesma topografia.

A paciente evoluiu com melhora do quadro motor de forma significativa em cerca de quatro semanas, sendo capaz de deambular normalmente. Na alta hospitalar, exibia somente leves disartria e dismetria.

Pacientes que desenvolvem hiponatremia durante o transplante hepático podem ser particularmente vulneráveis a desenvolver síndrome de desmielinização osmótica se a hiponatremia é rapidamente corrigida ${ }^{1}$. No caso da paciente em questão, a dosagem de sódio imediatamente antes do transplante era de $133 \mathrm{mEq} / \mathrm{L}$ e, 18 horas após a cirurgia, era de $143 \mathrm{mEq} / \mathrm{L}$, sugerindo que esta rápida correção poderia ter sido a responsável pelo quadro neurológico da paciente após o transplante hepático.

A característica patológica da síndrome da desmielinização osmótica é uma desmielinização não inflamatória com relativa preservação dos neurônios e axônios. Conforme a imagem exibida pela paciente, a desmielinização é mais frequentemente visualizada no centro da ponte ${ }^{2}$.

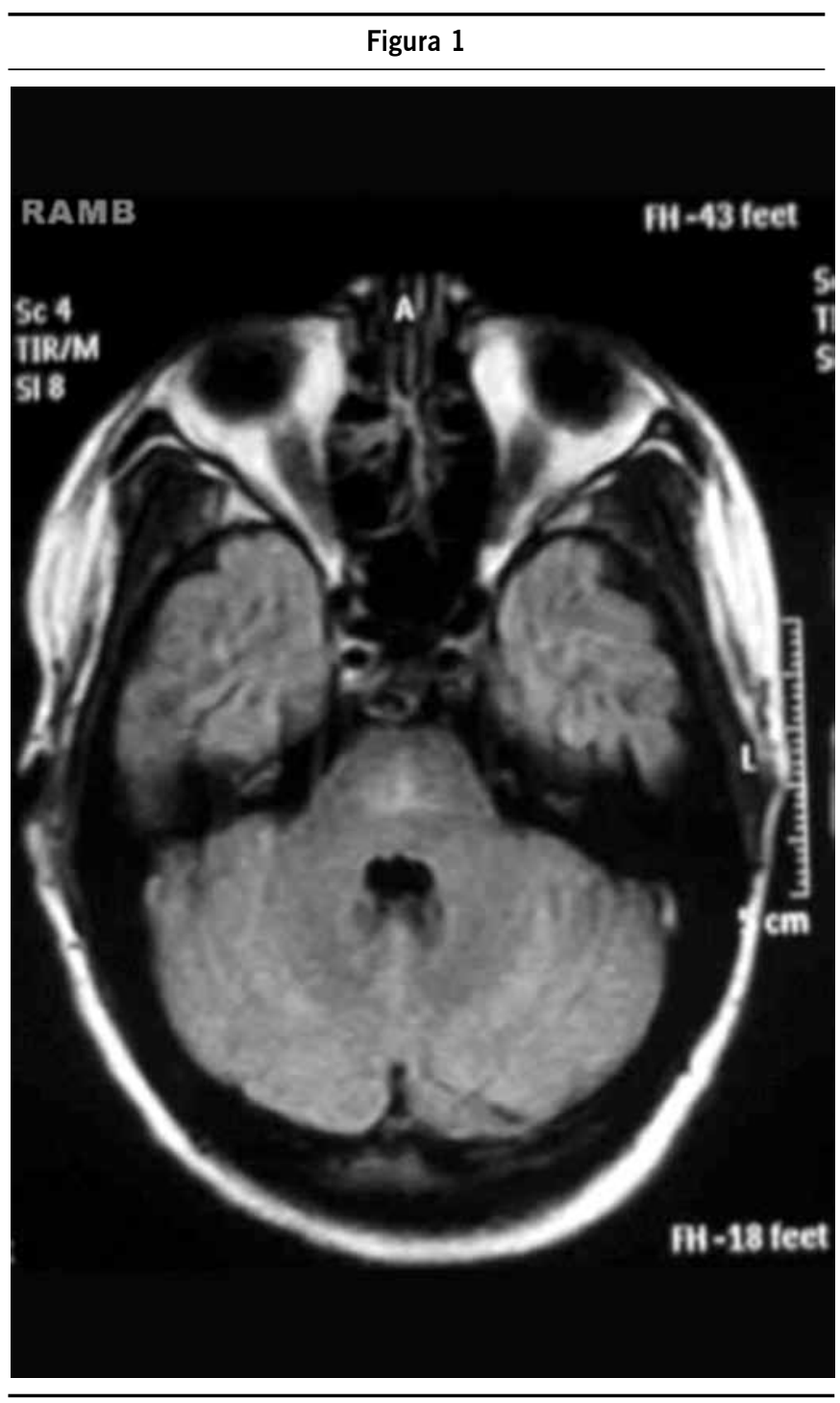

1. Médico - Residente em Neurologia do Hospital das Clínicas da Universidade Federal de Minas Gerais - UFMG, Belo Horizonte, MG

2. Médico - Serviço de Neurologia do Hospital das Clínicas da Universidade Federal de Minas Gerais - UFMG, Belo Horizonte, MG

3. Médico Neurologista - Professor do Departamento de Clínica Médica da Universidade Federal de Minas Gerais - UFMG, Belo Horizonte, MG

4. Doutor - Professor Adjunto do Departamento de Clínica Médica da Universidade Federal de Minas Gerais - UFMG, Belo Horizonte, MG 
Figura 2

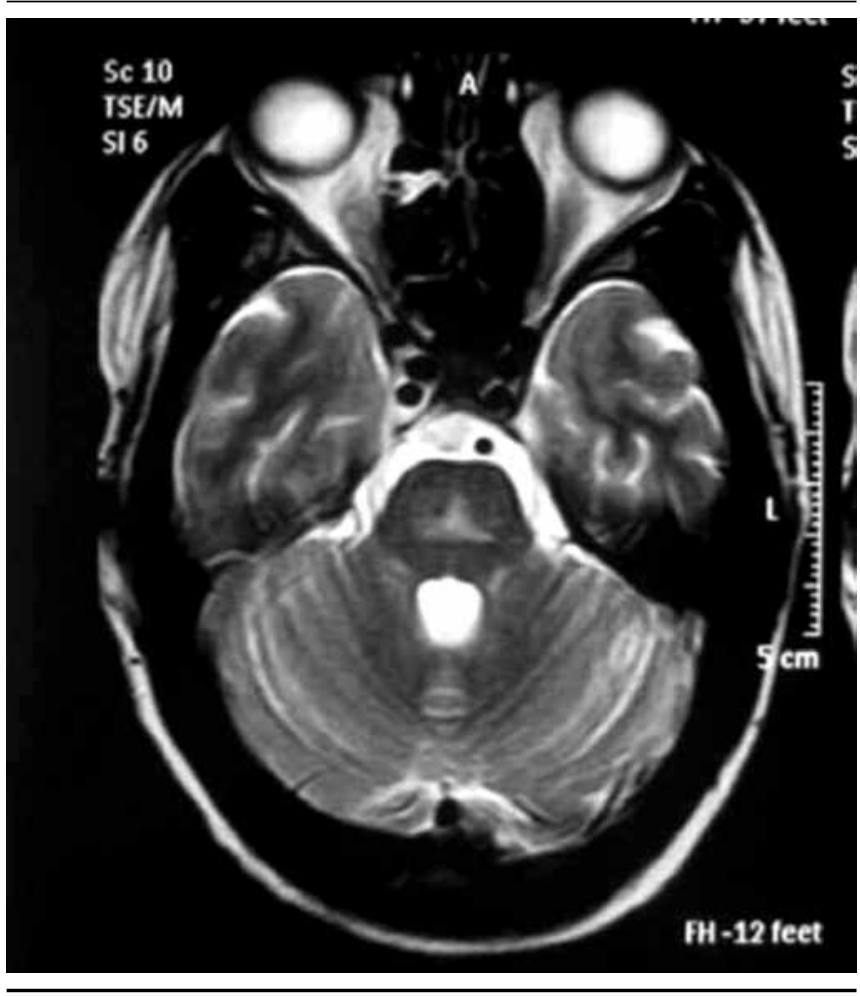

\section{REFERÊNCIAS}

1. Abbasoglu O, Goldstein RM, Vodapally MS, Jennings LW, Levey MF, Husberg $\mathrm{BS}$, et al. Liver transplantation in hyponatremic patients with emphasis on central pontine myelinolysis. Clin Transplant. 1998;12(3):263-9.

2. Gocht A, Colmant HJ. Central pontine and extrapontine myelinolysis: a report of 58 cases. Clin Neuropathol. 1987;6(6):262-70.

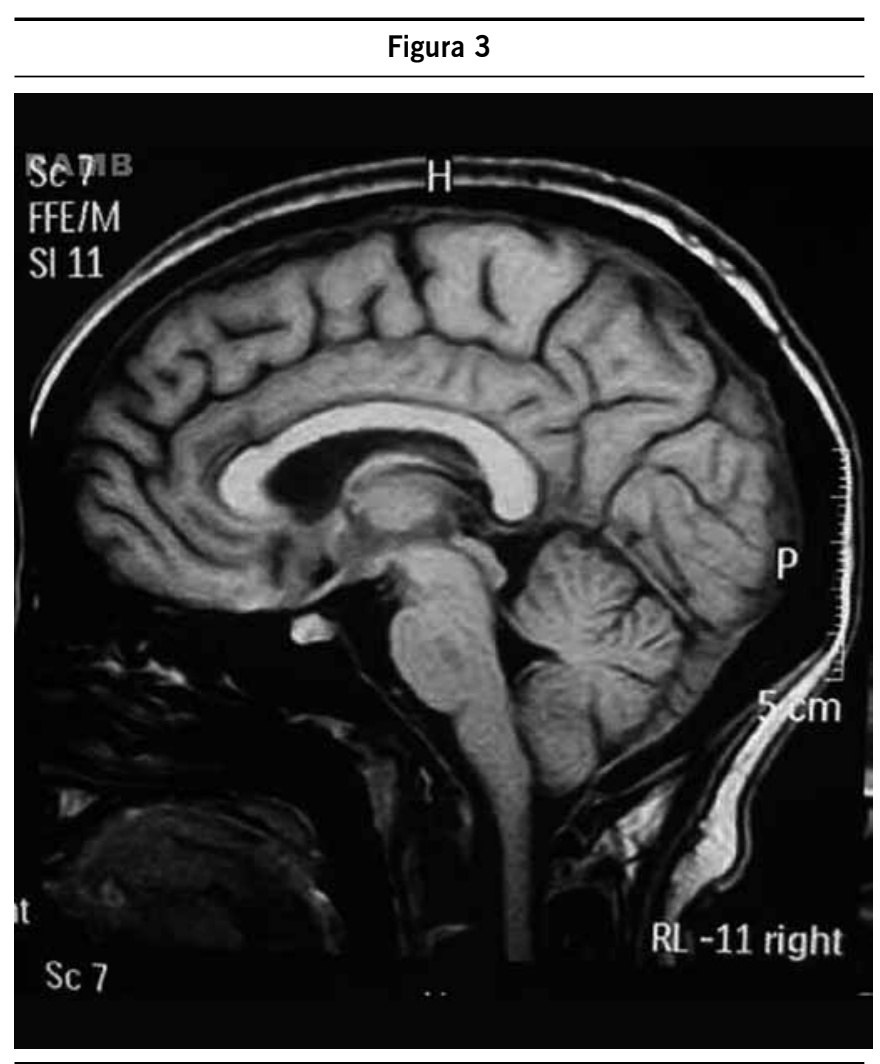

\section{*Correspondência:}

Departamento de Clínica Médica, Faculdade de Medicina - UFMG.

Av. Alfredo Balena, nº 190 Santa Efigênia

Belo Horizonte - MG

CEP: 30130-100

Telefone/Fax: (31) 3409-2651

E-mail: altexr@gmail.com 